\title{
Strutbiolipeurus rbeae Harrison, 1916 (Phthiraptera: Philopteridae) infestando avestruzes (Strutbio camelus) em uma criação no Município de Três Rios, RJ
}

\author{
Struthiolipeurus rheae Harrison, 1916 (Phthiraptera: Philopteridae) \\ infesting ostriches (Struthio camelus) in one farming in the Municipality of Três Rios, RJ \\ Thais F. Fagundes ${ }^{1}$; Carla A. Soleiro ${ }^{1}$; Rita de Cássia A. A. de Menezes²*
}

${ }^{1}$ Curso de Pós-Graduação em Ciências Veterinárias, Universidade Federal Rural do Rio de Janeiro - UFRRJ

${ }^{2}$ Departamento de Parasitologia Animal, Instituto de Veterinária, Universidade Federal Rural do Rio de Janeiro - UFRRJ

Recebido em 12 de Agosto de 2008

Aceito em 19 de Agosto de 2009

\section{Resumo}

No Brasil, a criação de avestruzes foi iniciada no final do Século XX, para suprir o mercado internacional de carne, plumas e couro. As plumas têm importância econômica nos setores industrial e artesanal. Os piolhos podem causar prurido intenso, que, dependendo da intensidade de infestaçáo, pode levar à depreciaçáo das plumas. No Estado do Rio de Janeiro, são desconhecidas as espécies de piolhos que infestam avestruzes. Assim, o objetivo deste trabalho foi identificar os piolhos que ocorrem nas aves pertencentes a um criatório comercial no Município de Três Rios. Nos anos de 2003 a 2006, mensalmente, as avestruzes foram examinadas, para verificar a presença de ectoparasitos. Quando constatada a infestação, algumas plumas foram retiradas, colocadas em sacos plásticos e enviadas ao laboratório para exame. Após serem coletados das plumas, os ectoparasitos foram examinados ao microscópio estereoscópio, clarificados em hidróxido de potássio a $10 \%$, desidratados em álcool etílico e montados em lâmina com balsamo do Canadá natural, para observação em microscópio óptico. Baseando-se na observação das características, foi possível determinar os espécimes coletados como pertencentes à espécie Struthiolipeurus rheae.

Palavras-chave: Avestruzes, Philopteridae, Struthiolipeurus rheae, Brasil.

\begin{abstract}
In Brazil ostriches farming began at the end of $20^{\text {th }}$ Century, to supply the international market of meat, feathers and leather. Feathers are economically important to industry and artisanal sectors. Lice can cause intense pruritus that depending on the intensity of infestation can lead to depreciation of feathers. In Rio de Janeiro there are unknown species of lice infesting ostriches. Thus the objective of this study was to identify the lice that happen in birds from commercial farms in the Municipality of Três Rios. From 2003 to 2006 ostriches were monthly examined for the presence of ectoparasites. When infestations were detected some feathers were removed, placed into plastic bags and sent to the laboratory for further analysis. After removed from feathers, ectoparasites were examined using a stereoscope, followed by clarification in $10 \%$ potassium hydroxide and dehydrated in ethanol. Permanent slides were mounted in natural Canada balsam for observation in optical microscope. Based on observed characteristics, it was possible to determine that collected specimens belong to the species Struthiolipeurus rheae.
\end{abstract}

Keywords: Ostriches, Philopteridae, Struthiolipeurus rheae, Brazil.

Estrutiocultura designa a criação racional de avestruzes, e origina-se do gênero a que pertence esta ave: Struthio. Essa atividade nasceu do interesse que a sociedade, do final do Século XIX e início do XX, tinha pelas plumas que eram obtidas junto à população silvestre dessas aves. Quando o número de avestruzes

\footnotetext{
*Autor para correspondência: Rita de Cássia A. A. de Menezes Departamento de Parasitologia Animal, Instituto de Veterinária, Universidade Federal Rural do Rio de Janeiro - UFRRJ,

Rodovia BR 465, km 7 CEP 23.890-000, Seropédica - RJ, Brasil e-mail: cassia@ufrri.br.

Apoio: FAPERJ (Primeiros Projetos)
}

selvagens foi reduzido drasticamente devido ao modismo, iniciou-se um programa de domesticação e criação desses animais na Ásia, Austrália, Américas do Norte e do Sul (CARRER, 2003).

Por volta do ano de 2003, a demanda do mercado internacional em termos de produçáo de carne, plumas e couro voltou a crescer e, com isso, a criaçáo de avestruzes passou a representar uma atividade em franca expansão, não só nos países de origem, mas em quase todo o mundo. No Brasil, a atividade foi iniciada por volta de 1997, com a importação dos primeiros reprodutores e matrizes de origem americana e dos países do sul da África, entre eles a Namíbia e África do Sul (CARRER, 2003). 
As plumas têm importância econômica por serem antiestáticas, sendo, então, utilizadas na indústria de eletroeletrônica e automobilística. Por atingirem até $65 \mathrm{~cm}$ de comprimento, são usadas em fantasias e adereços, o que faz do Brasil o maior mercado importador (SÍTIO AVESTRUZ, 2008).

Piolhos mastigadores e ácaro são muito encontrados em aves silvestres (VALIM et al., 2005), porém poucos trabalhos têm sido publicados sobre o assunto, principalmente em avestruzes.

Piolhos têm sua transmissão por contato direto entre os animais, e infestações por esses ectoparasitos são importantes por interferir na qualidade da pele e do couro, em razão do prurido intenso que causam e a consequente perda excessiva de plumas, além de causar estresse e predispor as aves a infecçōes secundárias e desordens gastrintestinais, por exemplo, impacção (COOPER, 2005).

A abundância e localizaçáo dos piolhos nas aves estão associadas à estação do ano, temperatura, luminosidade, umidade e condiçóes corporais do hospedeiro (PONCE GORDO et al., 2002).

Várias espécies de piolhos mastigadores ocorrem em ratitas, mas apenas o gênero Struthiolipeurus tem sido encontrado nos Estados Unidos. Struthiolipeurus struthionis ocorre em avestruzes, e as espécies $S$. rheae, $S$. nandu e $S$. renschi têm sido identificadas em emas na América do Norte (WEISBROTH; SEELIG, 1974).

No Brasil, Sinkoc et al. (2005) realizaram estudo com ectoparasitos de emas provenientes de Araxá em Minas Gerais, Porto Alegre, Pelotas e Passo Fundo no Rio Grande do Sul, e todas as amostras foram identificadas como $S$. rheae. No zoológico de São Paulo, em estudo realizado por Valim et al. (2005), foram encontrados espécimes machos e fêmeas de $S$. struthionis infestando S. camelus.
No Estado do Rio de Janeiro, são desconhecidas as espécies de piolhos que infestam avestruzes. Assim, o objetivo deste trabalho foi identificar a espécie que ocorre nas aves pertencentes a um criatório comercial localizado no Município de Três Rios.

Foram utilizadas avestruzes pertencentes a um criatório, localizado no Município de Três Rios, Estado do Rio de Janeiro. Entre 2003 e 2006, mensalmente, as avestruzes foram examinadas de modo não-aleatório, com o propósito de verificar a presença de ectoparasitos em suas plumas, independentemente do sexo e faixa etária. Quando constatada a infestação, algumas plumas foram retiradas e colocadas em sacos plásticos para o transporte até o laboratório. Os ectoparasitos coletados das plumas, por meio de pinçamento, foram mantidos em álcool $70{ }^{\circ} \mathrm{GL}$ e examinados ao microscópio estereoscópio. Em seguida, os espécimes foram clarificados em hidróxido de potássio a 10\%, desidratados em álcool etílico em concentraçóes crescentes de $70^{\circ}$ a $100{ }^{\circ} \mathrm{GL}$, de acordo com Weisbroth e Seelig (1974), e montados em lâmina, utilizando-se o bálsamo do Canadá natural para observação em microscópio óptico.

Foram coletados espécimes nas plumas das asas de aves jovens (até 12 meses) e adultas (com mais de 12 meses), respectivamente, nos meses de dezembro de 2003 e junho de 2004.

Ao microscópio estereoscópio, verificou-se que eram insetos da ordem Phthiraptera, subordem Ischnocera, família Philopteridae, do gênero Struthiolipeurus Cummings, 1916. Foi observada cabeça com formato mais longo que largo, e arredondada anteriormente, concordando com a descriçáo de Weisbroth e Seelig (1974) para S. rheae e, no abdômen, de acordo com Carriker (1945), a presença de pares de placas paratergais, nos segmentos I ao VII (Figuras 1a e 1b).

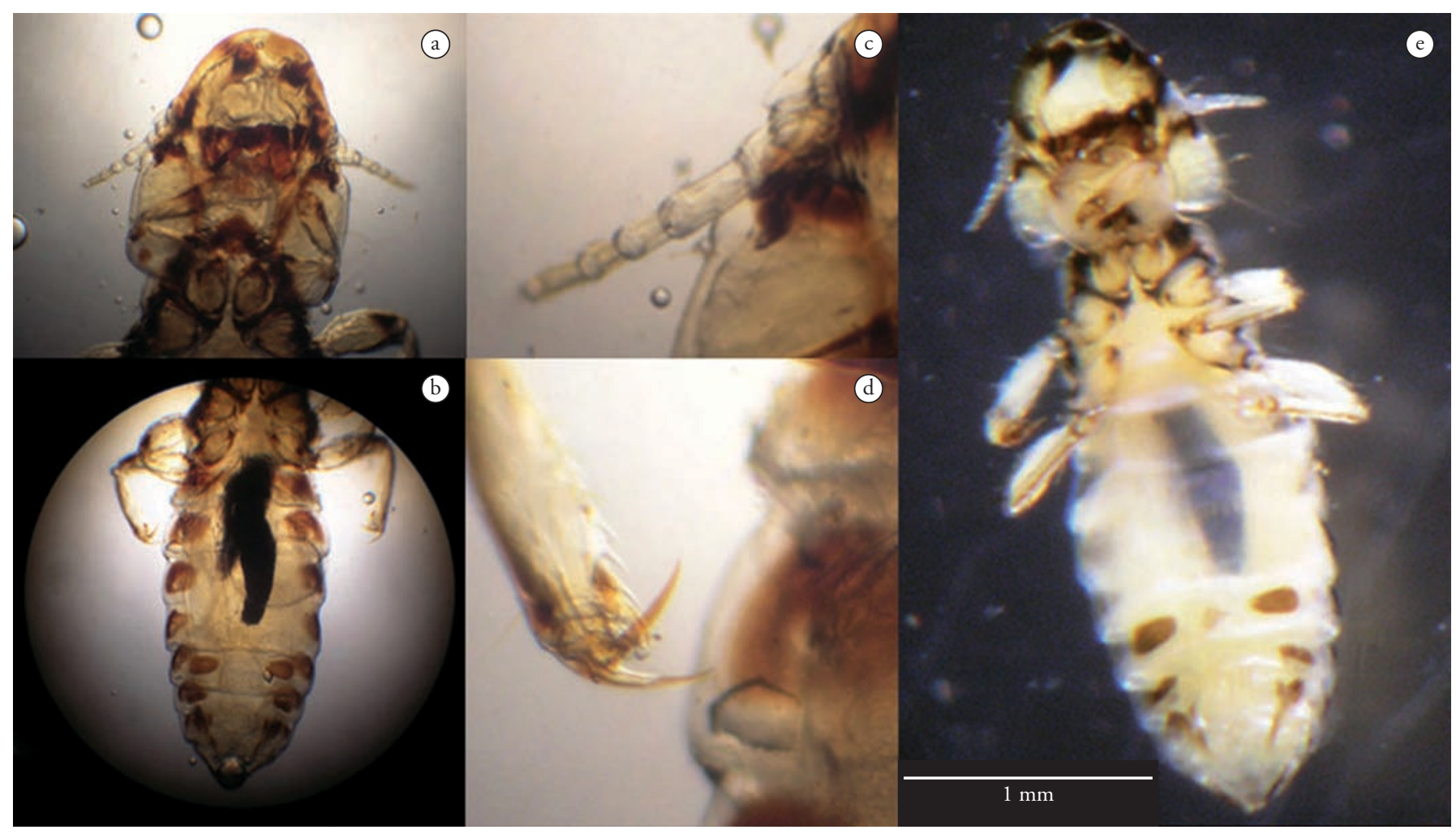

Figura 1. Struthiolipeurus rheae. a-d ao microscópio óptico. a: cabeça (40×); b: placas paratergais nos segmentos abdominais (I ao VII); c: detalhe da antena com cinco segmentos $(100 \times)$; d: garras tarsais do mesmo comprimento (100x); e: fêmea em vista ventral ao microscópio estereoscópio. 
Com base no descrito por Carriker (1945), ao microscópio óptico confirmou-se a identificação de $S$. rheae, a antena com cinco segmentos, sendo o primeiro mais largo que o terceiro (Figura 1c) e garras tarsais de iguais comprimentos (Figura 1d). Ventralmente, nos segmentos abdominais havia três pares de manchas escuras de acordo com o descrito por Carriker (1945), Weisbroth e Seelig (1974) e Cooper e Doumani (2006) para fêmeas dessa espécie (Figura 1e).

Em um estudo realizado na Europa por Ponce Gordo et al. (2002), com duração de quatro anos, duas espécies desse gênero - $S$. rheae e $S$. nandu - foram relatadas, porém, $S$. rheae foi encontrada parasitando avestruzes durante quase todo o período. Conforme citam os autores, algumas aves tinham alta intensidade de infestação e apresentavam grande perda de plumas na região dorsal próximo à cauda. Essa observaçáo difere do encontrado nas aves do criatório de Três Rios, que manifestaram queda e danos nas plumas das asas.

Embora S. struthionis seja o piolho mais comumente encontrado em avestruzes, acometendo severamente aves jovens (VAN HERDEEN et al., 1983), outras espécies do gênero, S. rheae, $S$. nandu, S. renschi, também ocorrem em ratitas, como pode ser detectado no presente estudo e em outros realizados, nesta década, no Brasil (SINKOC et al., 2005; VALIM et al. 2005).

Diante do presente diagnóstico, as criaçóes comerciais estabelecidas no Brasil e, em particular, no Estado do Rio de Janeiro, devem manter constante vigilância com o propósito de controle desses ectoparasitos. Visto que podem trazer prejuízos traduzidos pelo prurido intenso, fazendo com que as aves parem de se alimentar e se lesionem por arranhaduras e arrancamento das penas, e as aves jovens podem ter comprometimento do ganho de peso, debilidade e óbito.

\section{Agradecimentos}

Ao Dr. Luiz Eduardo Roland Tavares pelo auxílio na montagem das lâminas.

\section{Referências}

CARRER, C. da C. Os desafios do mercado de avestruzes no Brasil. Revista A Lavoura, ano 106, n. 847, p.16-21, 2003.

CARRIKER Jr., M. A. New species of Struthiolipeurus, Multicola, Microtenia and Pseudocophorus. Boletín de Entomología Venezolana, v. 4, n. 4, p. 165-189, 1945.

COOPER, R. G. Bacterial, fungal and parasitic infections in the ostrich (Struthio camelus var. domesticus). Animal Science Journal, v. 76, n. 2, p. 97-106, 2005.

COOPER, R. G.; DOUMANI, H. A. A. The presence of quill mites (Gabucinia bicaudata) and lice (Struthiolipeurus struthionis) in ostrich wing feathers. Journal of the South African Veterinary Association, v. 77 , n. 1 , p. 9-11, 2006.

Van HERDEEN, J.; HAYES, S. C., WILLIAMS, M. C. Suspected vitamin E- selenium deficiency in two ostriches. Journal of South African Veterinary Association, v. 54, n. 1, p. 53-54, 1983.

PONCE GORDO, F. P. et al. Parasites from farmed ostriches (Struthio camelus) and rheas (Rhea americana) in Europe. Veterinary Parasitology, v. 107 , n. $1 / 2$, p. $137-160,2002$.

SINKOC, A. L. et al. Ocorrência de Struthiolipeurus rheae (Phithiraptera: Ischnocera: Philopteridae) em Rhea americana (Rheiformes: Rheidae) no Brasil. Arquivos do Instituto de Biologia, v. 72, n. 4, p. 535-538, 2005.

Sítio Avestruz. Estrutiocultura. Disponível em: <http://www. sitioavestruz.com.br/estrutiocultura.asp >. Acesso em: Junho 2008.

VALIM, M. P. et al. Malófagos (Phthiraptera) recolhidos de aves silvestres no zoológico de São Paulo, SP, Brasil. Revista Brasileira de Entomologia, v. 49, n. 4 , p. $584-587,2005$.

WEISBROTH, S. H.; SEELIG, A. W. Struthiolipeurus rheae (Mallophaga: Philopteridae), an ectoparasite of the common Rhea (Rhea Americana). The Journal of Parasitology, v. 60, n. 5, p. 892-894, 1974. 